\title{
Economic Prospective of Small/Medium Nuclear reactors for Hybrid Seawater Desalination Systems
}

\author{
Ghada A. Al Bazedi*, Mohamed H. Sorour, Shadia R. Tewfik, Abdelghani M. G. Abulnour and Heba \\ A. Hani \\ Chemical Engineering and Pilot Plant Department, National Research Center, El-Bohouth Street, Dokki, P.O. Box 12622, Giza, Egypt
}

Received 2 December 2016; Accepted 18 August 2017

\begin{abstract}
Technical and economic analysis of the most recent reported world experience of small/medium nuclear reactors (SMRs)are essential to decision making regarding dual purpose power/water generation in developing countries. In this work, firstly, analysis of reported economic aspects concerning SMRs has been highlighted. A desalination system of 150,000 m3 water production capacity to cope with the need of small community (about 375,000 persons) has been then proposed. Technoeconomic study has been performed among small/medium reactors (SMR) to identify the appropriate power source for the integrated power desalination complex. IRIS nuclear reactor shows the lowest power cost of $\$ 0.029 / \mathrm{KWh}$ in the choice matrix of different SMRs with thermal output less than 1000 MWth. The selected reactor "IRIS" gives the ability to combine the desalination plant with a thermal desalination plant (MSF) type in a hybrid configuration scheme involving $\mathrm{MSF} / \mathrm{RO}$ with varying ratios. Sensitivity analysis of hybrid desalination process shows that, at MSF/RO ratio $11 \%$ the unit water cost is $\$ 0.77 / \mathrm{m} 3$, the lowest water cost has been approached for RO system $(0.73 \$ / \mathrm{m} 3)$ in an inverse relationship with permeate TDS. Empirical cost correlations have been developed for the corresponding permeates concentration.
\end{abstract}

\section{Introduction}

The International Atomic Energy Agency (IAEA) defines "small" reactor as a reactor built in modular arrangements with an electrical output less than $300 \mathrm{MWe}$, while "medium" reactor as one having electrical output between 300 and $700 \mathrm{MWe}$. The two sizes of reactors are combined into the common term of "small and medium-sized reactor" (SMR) representing reactors with electrical output less than 700MWe [1]. Typical small reactors are in operation in several countries e,g, Korea, USA and China, while other types of small reactors are under development such as HighTemperature Reactor (HTR) of output from 5 to $10 \mathrm{MWe}$ ,which is considered to be much safer, and is able to run for 5-10 years before requiring refueling or servicing [2-5]

"SMR" reactors are suitable for remote locations where specific energy output is required. This type of reactors has been proposed as an energy source for seawater desalination plants [2]. Due to significant enhancements in the reactor design that contribute to the upgraded safety requirements, installing small reactors systems is expected to have economic, safety and infrastructural benefits. Generally, modern small reactors for power generation are expected to have economy of mass production, reduced footprint costs,

\footnotetext{
*E-mail address: bazedi@yahoo.com

ISSN: $1791-2377 @ 2017$ Eastern Macedonia and Thrace Institute of Technology. All rights reserved. doi:10.25103/iestr.104.12
}

and a high level of passive safety in the event of malfunction [6].

Nuclear desalination is being discussed at the IAEA, in response to the request from countries affected by water shortage and desertification. Recently, several SMRs have been proposed by the member states of IAEA as an urgent and clean alternative for both energy source and potable water production [2]. Due to the experience gained in nuclear desalination, current developments and plans for nuclearpowered desalination based on different nuclear reactor types in many countries e.g.China, Egypt, Moroco, Algeria and USA [7].

There are two major types of desalination technologies broadly adopted classified as either thermal processes or membrane desalination processes. The main thermal processes are multi-stage flash distillation (MSF), multieffect distillation (MED) and vapour compression variants thermal and mechanical (TVC, MVC). The main membrane process is reverse osmosis ( $\mathrm{RO})[6]$.

Most of the desalination plants today are produced in "industrial-sized facilities". These include large thermal distillation plants in the Middle East with production capacities up to $1.6 \mathrm{Mm} 3$ /day. Seawater reverse osmosis (SWRO) is the dominant process worldwide, where plants distribution according to capacity is $59 \%$ which accounts for small $\left(1000 \mathrm{~m}^{3}\right.$ /day) representing only $5 \%$ of the worldwide production, while $2 \%$ repreaenting (42 large facilities) $\left(\leq 50,000 \mathrm{~m}^{3} /\right.$ day) account for almost $(45 \%)$ of the worldwide production [2]. 
The average investment cost required for engineering, procuring, and constructing a MSF distillation plant is about US $\$ 1235 / \mathrm{m}^{3}$ and the capital costs for "MED" and "SWRO" plants are with an average of US\$ $916 / \mathrm{m}^{3}$ and US\$ $641 / \mathrm{m}^{3}$ respectively. The average production costs of desalinated seawater are in the range of US\$ $0.45-0.60 \mathrm{~m}^{3}$, which varies according to capacity range and energy prices as desalination is an energy extensive process water production costs have risen - depending on the location, supply/demand, and technology adoped to US\$ $1-1.5 / \mathrm{m}^{3}[2,4]$.

This article addresses updated technical and economic analysis regarding SMR-hybrid sea water desalination complex as a key to future dual purpose power/water generation in developing countries.

\section{Approach and Methodology}

The adopted approach comprises review, categorization and compilation of SMRs according to reported technical and economic features. Economic aspects have been then thoroughly analyzed Simulation of a proposed nuclear desalination system of capacity $150,000 \mathrm{~m}^{3}$ water production has been developed using both WTCostIIC [8], which is a software for Modeling the Capital and Operating Costs of Thermal Desalination Processes in addition to Desalination Economic Evaluation Program (DEEP code) [9], whichare widely used for analysis of desalination systems. Figure 1, represents the flowchart of the adopted methodology.

\subsection{Technical and Economic Aspects of SMR}

SMRs distribution around the world has been investigated by being classified as operated, under construction, proposed or planned. The total number exceeds one hundred with total capacity around 700,000 MWe [10]. According to a previous review [7], there are seven land-based proven designs available for commercial use of SMRs.

\subsection{Integrated Desalination Plant Features}

A proposed desalination scheme is investigated with a capacity of $150,000 \mathrm{~m}^{3} / \mathrm{d}$.An economic assessment was undertaken using DEEP for the proposed SWRO desalination plant coupled with different reactor types. Selected schemes were investigated for energy consumption and related financial indicators. The choice matrix comprised nuclear/combined cycle, nuclear/ gas cycle and nuclear/steam cycle.

Cost comparison among possible alternatives aimed at identification of the least water production cost. Selected case based on minimum water production cost was then investigated coupled with different hybrid RO/MSF schemes using DEEP. Coupling RO and MSF with "nuclear steam supply system (NSSS)" will achieve some economical and technical advantages. Sensitivity analysis has been undertaken for different water production costs with different viable hybrid schemes.

\section{Results}

\subsection{Technical and Economic Aspects of SMR}

SMRs data have been reviewed compiled and analyzed according to technical and economic features. Table (1), presents a comparison between lowest costs of SMRs reactors while Table (2), illustrates the updated cost data of small and modular reactors (SMR) for 2015 using ENR [11].
Table 1. Comparison of the lowest costs of different reactor types

\begin{tabular}{c|c|c|c|c}
\hline $\begin{array}{c}\text { Reactor } \\
\text { Design }\end{array}$ & $\begin{array}{c}\text { Reactor } \\
\text { Type }\end{array}$ & Mwe & $\mathbf{\$} / \mathbf{k W e *}$ & Ref. \\
\hline IRIS & PWR & 335 & 1200 & 12 \\
CAREM- & PWR & 300 & $1200-$ & 12 \\
300 & & & 1300 & \\
VK-300 & BWR & 250 & 1100 & 12 \\
AHWR & HWR & 300 & 1300 & 13 \\
GT-MHR & GCR & 287 & 1200 & 12 \\
SVBR & FBR & 102 & 1200 & 14 \\
\hline *updated cost 2015 using ENR
\end{tabular}

As desalination is an energy intensive process, the cost of desalination is sensitive to the cost of energy. Coupling schemes have been calculated using DEEP code. Different schemes have been investigated for energy consumption and related financial indicators using the DEEP code. The choice matrix comprised nuclear/combined cycle, nuclear/gas cycle and nuclear/steam cycle. The apparent energy costs per kWh were $\$ 0.07,0.065$, and 0.058 respectively. The corresponding water production unit costs were $\$ 0.857$, 0.844 , and 0.824 per $\mathrm{m}^{3}$ respectively. The results were based on constant thermal output capacity of $1800 \mathrm{MWh}$, and different electrical output varying from 300-700 MWe with thermal utilization of $32 \%$ for power plant types gas cycle and steam cycle and $45 \%$ for combined cycle. The water to power ratio is $22 \%$ for gas cycle and steam cycle and $30 \%$ for combined cycle. It has been concluded that nuclear/steam cycle manifests the lowest unit energy and unit water costs.

A choice matrix have been investigated for lower thermal output reactors less than $1000 \mathrm{MWth}$; the water production cost is presented in Tables(3) and (4), where Table (3) presents the cost indicators of Nuclear-(Combined cycle/steam cycle)/RO desalination using default DEEP parameters, while Table (4) shows the economic indicators of Nuclear-(Combined cycle/steam cycle)/RO desalination using levelized updated cost values into DEEP. According to the results of the choice matrix presented, "International Reactor Innovative and Secure"IRIS reactor type shows the lowest power cost of $\$ 0.029 / \mathrm{KWh}$ for the levelized cost updated DEEP. The thermal output of the selected reactor "IRIS", which is almost 1000MWth, gives the ability to adopt thermal desalination plant using the thermal output from the reactor.

Another choice matrix has been investigated for lower thermal output reactors less than 1000 MWth for steam cycle hybrid desalination plant. Different hybrid capacities have been investigated. According to DEEP output results for nuclear-steam cycle hybrid desalination plant, "Gas Turbine Modular Helium Reactor (GT-MHR)" which is a nuclear fission power reactor design under development by a group of Russian enterprises gives the lowest water and power cost for steam cycle-hybrid nuclear powered desalination plant. Figure (2), shows a screen shot of an integrated case using DEEP.

This situation reflects that the nuclear power source for a given remote community will cover electrical/non-electrical applications. Moreover, electricity will be imported from the nuclear power plant with the cost concluded in Table (4). This cost indicator may be increased due to other factors e.g. overheads, cost of finance, rate of return... etc. 


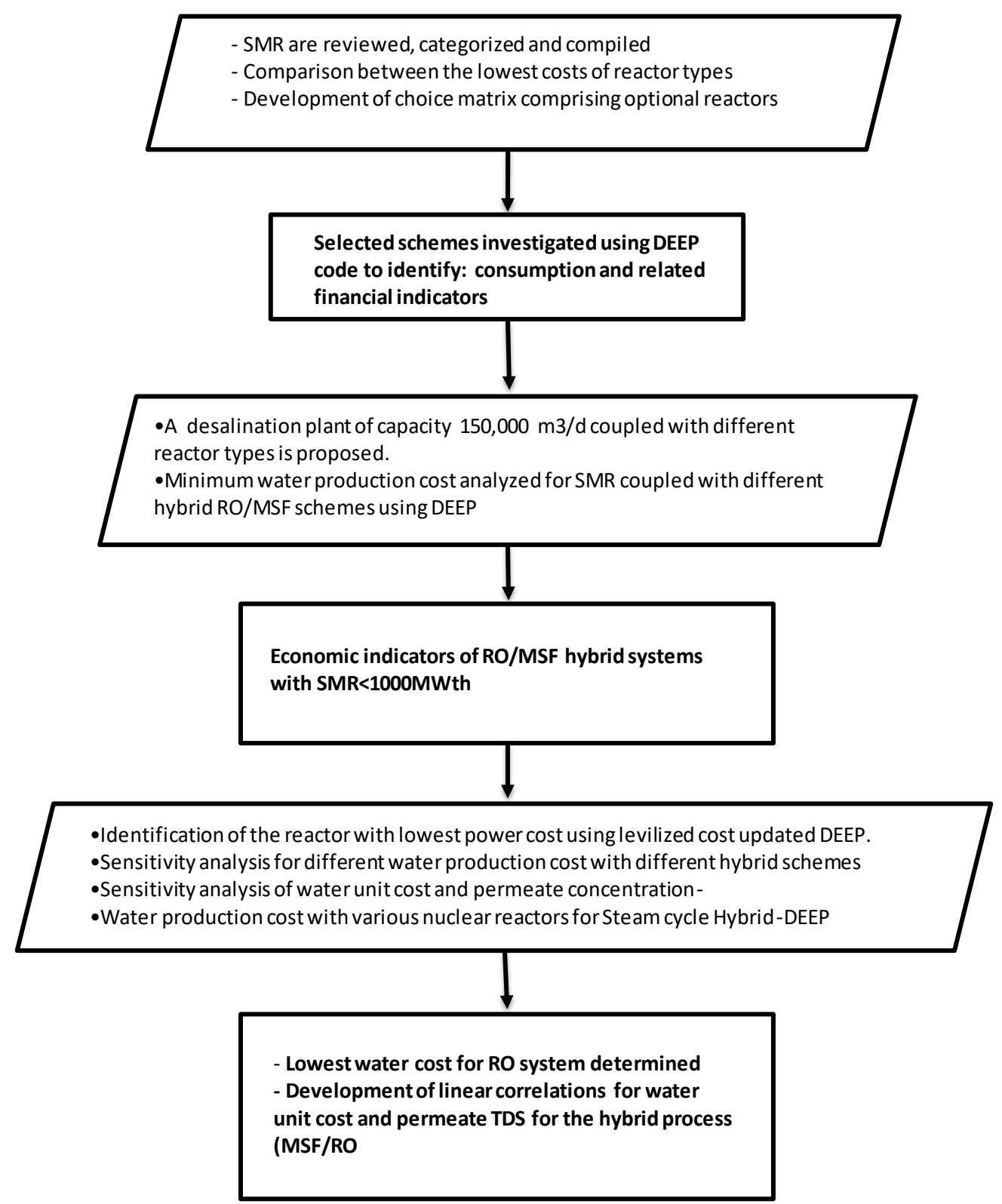

Fig. 1. Approach and Methodology flowchar

Table 2. UpdatedCost data for small modular SMR nuclear reactors

\begin{tabular}{l|l|c|c|c}
\hline Reactor Design & $\begin{array}{l}\text { Reactor } \\
\text { Type }\end{array}$ & $\begin{array}{c}\text { O\&M + Fuel costs } \\
\text { USD/MWh } \\
\mathbf{2 0 1 5}\end{array}$ & $\begin{array}{c}\text { Updated desalinated water cost } \\
\mathbf{\$} / \mathbf{m}^{\mathbf{3}} \mathbf{( 2 0 1 5 )}\end{array}$ & Ref. \\
\hline ABV & PWR & 39.79 & $<1.90$ & 14 \\
KLT-40S & PWR & 11.8 & 1.06 & 15 \\
SMART & PWR & 16.7 & 0.83 & 12 \\
CAREM-300 & PWR & & 1.24 & 12 \\
PHWR-220 & HWR & 24.8 & & 16 \\
HTR-PM & HTGR & 12 & & 12 \\
PBMR & HTGR & 14.4 & & 12 \\
GT-MHR & HTGR & & & \\
\hline
\end{tabular}


Table 3. Cost Indicators of Nuclear-Combined cycle/steam cycle RO desalination using default DEEP parameters.

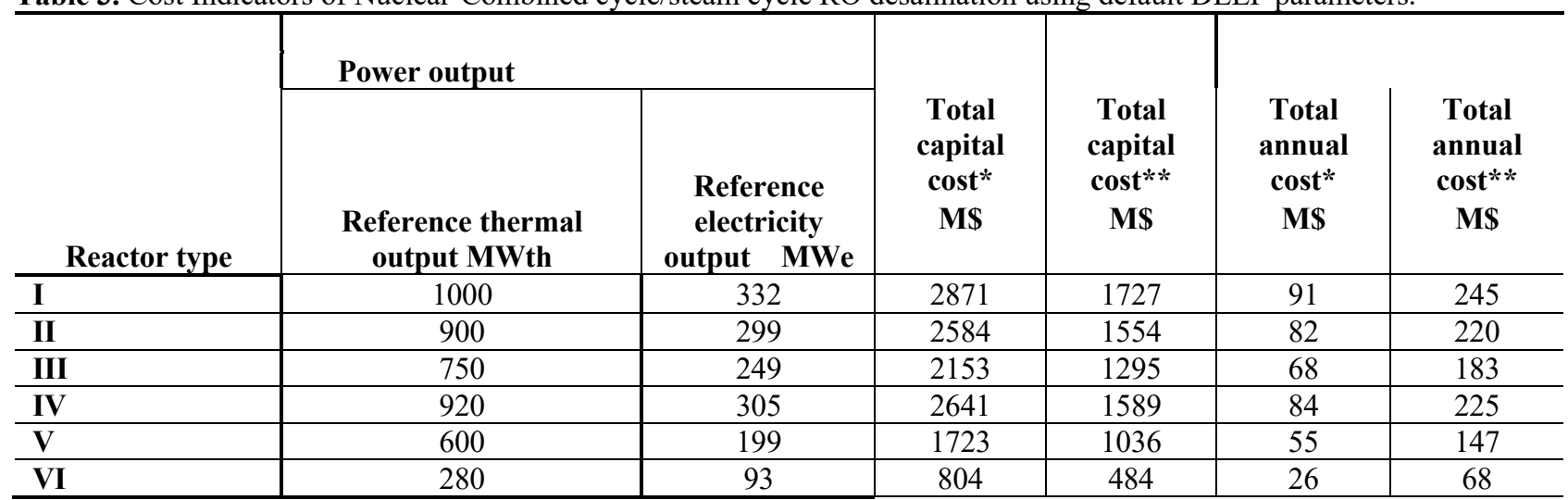

*combined cycle

**steam cycle

Table4. Cost Indicators of Nuclear combinedcycle and steam cycle /RO desalination using levelized updated cost values into DEEP.

\begin{tabular}{|c|c|c|c|c|c|c|c|c|}
\hline \multirow[b]{2}{*}{ Reactor type } & \multicolumn{2}{|c|}{ Power output } & \multirow[b]{2}{*}{$\begin{array}{c}\text { Total } \\
\text { capital } \\
\text { cost }^{*} \\
\text { MS }\end{array}$} & \multirow[b]{2}{*}{$\begin{array}{c}\text { Total } \\
\text { annual } \\
\text { cost }^{*} \\
\text { M\$ }\end{array}$} & \multirow[b]{2}{*}{$\begin{array}{c}\text { Total } \\
\text { capital } \\
\text { cost }^{* *} \\
\text { M\$ }\end{array}$} & \multirow[b]{2}{*}{$\begin{array}{c}\text { Total } \\
\text { annual } \\
\text { cost }^{* *} \\
\text { MS }\end{array}$} & \multirow{2}{*}{$\begin{array}{l}\text { Power } \\
\text { \$/kWh }\end{array}$} & \multirow{2}{*}{$\begin{array}{l}\text { Power } \\
\text { \$/kWh }\end{array}$} \\
\hline & $\begin{array}{c}\text { Reference } \\
\text { thermal } \\
\text { output MWth }\end{array}$ & $\begin{array}{c}\text { Reference } \\
\text { electricity } \\
\text { output } \\
\text { MWe } \\
\end{array}$ & & & & & & \\
\hline IRIS & 1000 & 310 & 529 & 103 & 686 & 88 & 0.029 & 0.036 \\
\hline Carem300 & 900 & 495 & 782 & 115 & 530 & 75 & 0.036 & 0.034 \\
\hline VK-300 & 750 & 412 & 597 & 93 & 404 & 60 & 0.035 & 0.033 \\
\hline AHWR-220 & 920 & 506 & 886 & 122 & 586 & 79 & 0.038 & 0.035 \\
\hline GTMHR & 600 & 330 & 521 & 77 & 353 & 50 & 0.036 & 0.034 \\
\hline SVBR & 280 & 154 & 243 & 36 & 161 & 23 & 0.036 & 0.036 \\
\hline
\end{tabular}

*combined cycle

**steam cycle

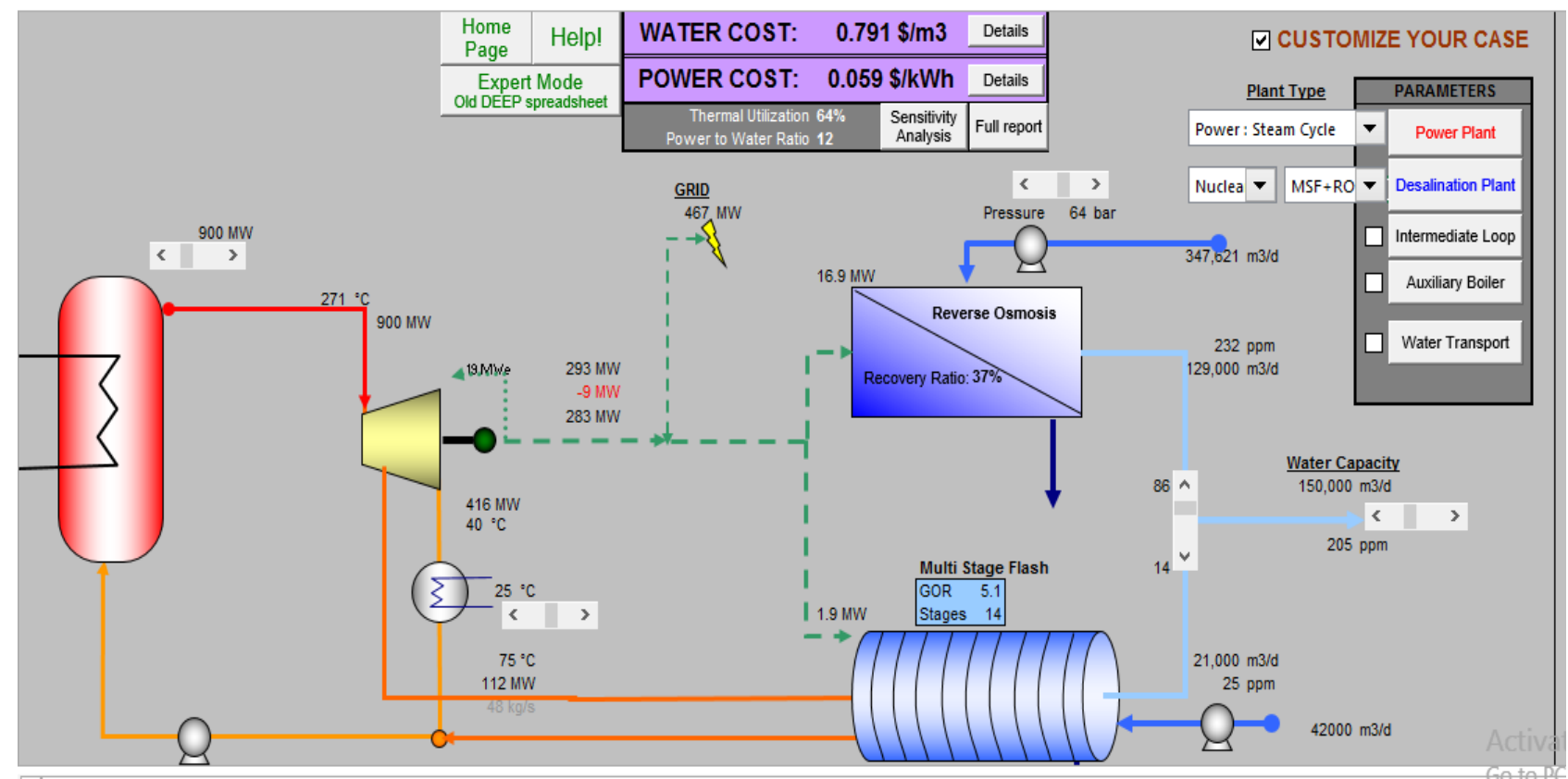

Fig. 2. Simulated case using DEEP

\subsection{Integrated Desalination Plant Features}

Hybrid desalination plants with different output ratios has been investigated using DEEP with power cost assumed to be
$\$ 0.03 / \mathrm{KWh}$. The results of the simulation are presented inTable (5) andFigures(3) and (4). 
Table 5. Water production cost with different hybrid schemes of the optimized case

\begin{tabular}{cccc}
\hline Water Cost $\mathbf{\$} / \mathbf{m}^{\mathbf{3}}$ & RO Capacity $\mathbf{~ m}^{\mathbf{3}} / \mathbf{d a y}$ & MSF capacity $\mathbf{~ m}^{\mathbf{3}} \mathbf{\text { d }}$ & permeate TDS $\mathbf{~ p p m ~}$ \\
\hline 0.747 & 150,000 & 0 & 254 \\
1.074 & 45,000 & 105,000 & 90 \\
1.021 & 60.000 & 90,000 & 110 \\
0.969 & 75.000 & 75,000 & 130 \\
0.924 & 90,000 & 60,000 & 150 \\
0.872 & 105,000 & 45,000 & 170 \\
0.821 & 120,000 & 30,000 & 189 \\
0.772 & 135,000 & 15,000 & 207 \\
1.241 & 0 & 150,000 & 25 \\
1.184 & 15,000 & 135,000 & 47 \\
1.15 & 22,500 & 127,500 & 58 \\
\hline
\end{tabular}

\subsection{Sensitivity Analysis}

Sensitivity analysis on using hybrid nuclear desalination system (MSF/RO) has been carried out.The sensitivity of water unit cost in $\$ / \mathrm{m}^{3}$ and the concentration of permeate in $\mathrm{ppm}$ as a function of (\% system integration)for sea water desalination system $\left(150,000 \mathrm{~m}^{3} / \mathrm{d}\right)$ powered by nuclear reactor is illustrated in Figures (3) and (4).It has been indicated that the lowest water cost has been approached for pure RO system $\left(0.73 \$ / \mathrm{m}^{3}\right)$ in an inverse relationship with permeate TDS (the corresponding permeate concentration is $225 \mathrm{ppm})$. At $\mathrm{MSF} / \mathrm{RO}$ ratio $11 \%$ at which an acceptable product water TDS of $200 \mathrm{mg} / \mathrm{l}$ is achieved, the produced unit water cost is $\$ 0.77 / \mathrm{m}^{3}$. Empirical correlations developed from the simulation results of using IRIS nuclear reactor with hybrid MSF/RO,indicatesthat both relations are linearas follows(withcorrelation coefficients exceeding 0.99):

$$
\mathrm{C}=\quad-0.0058(\% \mathrm{RO})
$$

1.2877

TDS $=$ $1.99(\% \mathrm{RO})$

\section{(2)}

where :

$\mathrm{C}$ is the unit water cost in $\$ / \mathrm{m}^{3}$

$\% \mathrm{RO}$ is the $\mathrm{MSF} / \mathrm{RO}$ ratio

TDS is the permeate concentration in ppm

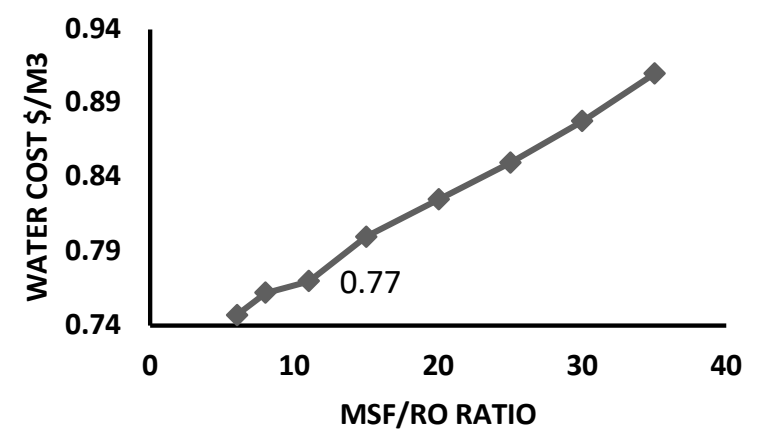

Fig. 3. Sensitivity analysis for different RO/MSF ratios

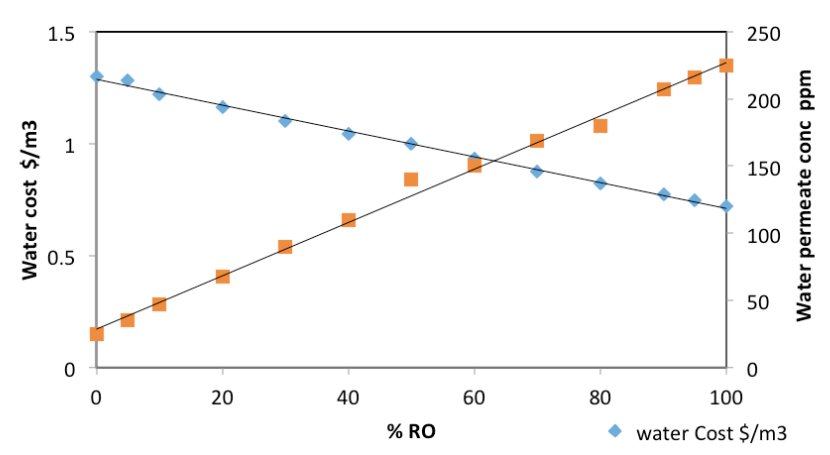

Fig. 4. Sensitivity analysis of water unit cost and permeate concentration

Detailed data on nuclear desalination for high capacities for the adopted technologies are sparse. However, to enable validation of our results we refer to the work of Yan, X.L., et al., 2016 and S.U.-D. Khan, et al., 2016 as follows:

- The water cost with the GTHTR300 cogeneration is US $\$ 0.57 / \mathrm{m} 3$ for a desalination capacity 54,552 $\mathrm{m} 3 /$ day with a unit power cost of $\$ 0.035 / \mathrm{kWh}$ [17]

- Identified outputs based on studies from IAEA for nuclear desalination plants in the range of 80 $100,000 \mathrm{~m} 3 /$ day to $200-500,000 \mathrm{~m} 3 /$ day, showed that unit water cost range is US\$ 0.5 to $0.94 / \mathrm{m}^{3}$ for RO, US\$ 0.6 to $0.96 / \mathrm{m}^{3}$ for MED, and US\$ 1.18 to $1.48 / \mathrm{m} 3$ for MSF processes [18].

$$
\bullet
$$

These values are in agreement with the findings of this work

\section{Conclusions}

Due to technological advances in nuclear reactor design and safety, SMRs are strongly recommended in offering energy with high reliability, passive safety and economic competitiveness. SMRs construction time is about $1 / 3$ of large reactors, with lower financial risk and unit capital M\$/MWe. A desalination system of $150,000 \mathrm{~m}^{3}$ water production capacity to cope with the need of small communities has been proposed and analyzed. The desalination system requires about 19.1 MWe, SMR reactor type being proposed as a power source. Techno- economic study has been performed to compare between different SMR types to select preferred technical and economic features. For the proposed desalination scheme powered by IRIS nuclear reactor, the lowest power cost has been estimated to be $\$ 0.029 / \mathrm{KWh}$ using updated levelized cost. The thermal output of the selected reactor "IRIS", which is almost 1000 MWth, gives 
the ability to combine the desalination plant with thermal desalination plant type to use the thermal output from the reactor. Sensitivity analysis of hybrid desalination process shows that according to different $\mathrm{MSF} / \mathrm{RO}$ ratio the unit water costs varies linearly. At MSF/RO ratio $11 \%$, the unit water cost is $\$ 0.77 / \mathrm{m}^{3}$ at corresponding permeate TDS $200 \mathrm{ppm}$. The lowest water cost has been approached for RO system $\left(0.73 \$ / \mathrm{m}^{3}\right)$ in an inverse relationship with permeate TDS (the corresponding permeate concentration is 225 ppm).Linearcorrelations for water unit cost and permeate TDS have been developed for the hybrid process (MSF/RO) withcorrelation coefficients exceeding 0.99 .

\section{Acknowledgement}

This work was financially supported by the Science and Technology Development Fund (STDF) of Egypt, under grant number STDF/1689. The authors would like to express their acknowledgement to the late Dr. SafaaAbd El Raouf Ahmed, who was the team leader of this project and had passed away before finalization of this article.

This is an Open Access article distributed under the terms of the Creative Commons Attribution Licence

\section{References}

1. C. Hasting, UNDP, United Nations Development Program, Water rights and wrongs, (UNDP,2007),p 15

2. S. Lattemann , D. Maria Kennedy, C. Jan Schippers and G. Amy, Global desalination situation, Sustainability Science and Engineering V2: Chapter 2: Global Desalination Situation, 2009, pp 7-39. Print Book ISBN :9780444531155

3. M. Hadid Subki, Update on SMR Technology Status and IAEA Programme on Common Technology and Issues for SMRs, INPRO Dialogue Forum on NE Innovations: CUC for SMR, 10 - 14 October 2011

4. WNA, World Nuclear Association, World Nuclear Power Reactors \& Uranium Requirements, June 2016 http://www.worldnuclear.org/info/Facts-and-Figures/World-Nuclear-PowerReactors-and-Uranium-Requirements/\#.UUW9g9ZTDSg

5. B. J. Csik, Assessment of the world market for small and medium reactors, XA9846716, International Atomic Energy Agency, Vienna, (2015)

6. Global Water Intelligence (GWI), Desalination market returns, V.11, Issue 7, 2010

7. Safaa Abdelraouf Ahmed, Heba Ahmed Hani, Ghada Ahmed Al Bazedi, Mayyada M. H. El-Sayed, and Abdelghani M. G. Abulnour, Small/medium nuclear reactors for potential desalination applications : Mini review, Korean J. Chem. Eng., 31(6), 924-929 (2014)

8. Irving Moch, Jr., William R. Querns, and Darlene Steward, WT Cost II Modeling the Capital and Operating Costs of Thermal Desalination Processes Utilizing a Recently Developed Computer Program that Evaluates Membrane Desalting, Electrodialysis, and Ion Exchange Plants, USBR Report 130, 2008
9. https://www.iaea.org/NuclearPower/NEA Desalination/index.html

10. Robert Rosner et al Small Modular Reactors - Key to Future Nuclear Power Generation in the U.S. Energy Policy Institute at Chicago, Technical Paper, Revision 1,November ( 2011) 1-73

11. http://www.enr.com

12. IAEA (2006), status of Innovative Small and Medium Sized Reactor Designs 2005: Reactors with conventional Refueling schemes, IAEA-TECDOC-1485, Vienna, Austria

13. Antony, A. (2008), Economic Competitiveness of the Indian Advanced Heavy Water Reactor (AHWR), BARC, India

14. IAEA (2007), Status of SmallReactor Designs without On-site Refuelling,IAEA-TECDOC-1536, Vienna, Austria.

15. E. Hassan, S. Fath, Fatma M. El-Shall and Ulrike Seibert \& Gisela Vogt, A Stand Alone Complex For The Production Of Water, Food, Electricity \& Salts For The Sustainable Development of Small Communities In Remote Areas, Ninth International Water Technology Conference, IWTC9, Sharm El-Sheikh, Egypt, 2005

16. IAEA (2007), status ofNuclear Desalination in IAEA Member States,IAEA-TECDOC-1524

17. Yan, X.L., et al., GTHTR300 cost reduction through design upgrade and cogeneration. Nucl. Eng. Des. (2016), http://dx.doi.org/10.1016/j.nucengdes.2016.02.023

18. S.U.-D. Khan, et al., Development and techno-economic analysis of small modular nuclear reactor and desalination system across Middle East and North Afr..., Desalination (2016), http://dx.doi.org/10.1016/j.desal.2016.05.008

\begin{tabular}{ll}
\multicolumn{1}{c}{ Appendix } & Boiling Water Reactor \\
BWR & Gas Turbine Modular Helium Reactor \\
GT-MHR & High Temperature Gas Reactor \\
HTGR & High Temperature Reactor \\
HTR & International Atomic Energy Agency \\
IAEA & Multistage Flash Distillation \\
MSF & Mega Watt electric \\
MWe & Mega Watt thermal \\
MWth & Pebble Bed Modular Reactor \\
PBMR & Pressurized Water Reactor \\
PWR & Reverse Osmosis \\
RO & Small Medium/Modular Reactor \\
SMR & Sea Water Reverse Osmosis \\
SWRO & International Reactor Innovative and Secure \\
IRIS & Central Argentina de ElementosModulares \\
CAREM-300 & Advanced heavy-water reactor \\
AHWR & "Svintsovo-VismutovyiBystryiReaktor" - lead-bismuth fast reactor \\
SVBR &
\end{tabular}

